\title{
Formation of Van Der Waals Complexes in Concerted Unimolecular Elimination Processes
}

\author{
Faina Dubnikova and Assa Lifshitz \\ The Institute of Chemistry, The Hebrew University of Jerusalem, Edmond J. Safra Campus, Jerusalem 91904, Israel \\ Correspondence should be addressed to Assa Lifshitz, assa@vms.huji.ac.il
}

Received 8 January 2012; Accepted 1 February 2012

Academic Editors: A. M. Koster and S. Sasaki

Copyright ( $) 2012$ F. Dubnikova and A. Lifshitz. This is an open access article distributed under the Creative Commons Attribution License, which permits unrestricted use, distribution, and reproduction in any medium, provided the original work is properly cited.

\begin{abstract}
Potential energy surfaces for three unimolecular elimination reactions: $\left(\mathrm{CH}_{3}\right)_{3} \mathrm{C}-\mathrm{OH} \rightarrow\left(\mathrm{CH}_{3}\right)_{3}=\mathrm{C}=\mathrm{CH}_{2}+\mathrm{H}_{2} \mathrm{O}, \mathrm{CH}_{3}-\mathrm{CF}_{3} \rightarrow$ $\mathrm{CH}_{2}=\mathrm{CF}_{2}+\mathrm{HF}$, and $\mathrm{CH}_{3}-\mathrm{CH}_{2}-\mathrm{CH}_{2} \mathrm{Cl} \rightarrow \mathrm{CH}_{3}-\mathrm{CH}=\mathrm{CH}_{2}+\mathrm{HCl}$ were calculated using a variety of quantum chemical methods. It was shown that, in all the three cases, the transition state in the first step of the reaction leads to the production of the complex intermediates based on van der Waals interactions. In addition to the fact that the three complexes appear as intermediates on the potential energy surfaces, which means that they are not free entities, the entropy values of the two elimination products are far above those of the complexes due to their additional Sackur-Tetrode entropy. Moreover, the three vibrational frequencies of the $\mathrm{H}_{2} \mathrm{O}$ group in the $\left(\mathrm{CH}_{3}\right)_{3} \mathrm{COH}$ complex and the $\mathrm{H}-\mathrm{Cl}$ and $\mathrm{H}-\mathrm{F}$ stretch frequencies in $\mathrm{CH}_{3} \mathrm{CF}_{3}$ and $\mathrm{CH}_{3} \mathrm{CH}_{2} \mathrm{CH}_{2} \mathrm{Cl}_{\text {are }}$ quite different (see the various tables). The energy levels of the complexes were found to be below those of the corresponding decomposition products. Rate constants for the elimination processes were calculated from the potential energy surfaces using transition-state theory and were compared to available experimental data.
\end{abstract}

\section{Introduction}

There is a large number of thermal unimolecular elimination reactions where part of a molecule is eliminated from a large organic one. Among them, elimination of $\mathrm{H}_{2} \mathrm{O}, \mathrm{HCl}, \mathrm{HF}$, and others from various types of organic molecules such as alcohols and halogenated hydrocarbons [1-6]. The potential energy surfaces describing the unimolecular eliminations were believed for quite a while to be rather simple processes where the reactant generates the products via one transition state with no intermediates.

The structure and the energetics of complexes, such as van der Waals complexes, hydrogen bonds, and others have recently been discussed in the literature [7-10]. We have shown in the past [11] that the potential energy surfaces of hydrogen bond, and van der Waals complex existed, for example, prior to the $\mathrm{H}_{2}$ elimination from 2,3-dihydrobenzofuran to produce benzofuran and hydrogen. In the present study we have looked at three additional systems for further support of our previous findings in the $\mathrm{H}_{2}$ elimination process from 2,3-dihydrobenzofuran. We could not find much additional support in the literature for the fact that such complexes are found in unimolecular gas phase elimination processes. A recent work by El-Nahas et al. [12] describes a very reliable structures and energetics of several unimolecular eliminations on the basis of quantum chemical calculations, but it hardly provides a discussion of whether these proceed via one or two step mechanisms.

We have found in the following three reaction systems

$$
\mathrm{CH}_{3}-\mathrm{CH}_{2}-\mathrm{CH}_{2} \mathrm{Cl} \longrightarrow \mathrm{CH}_{3}-\mathrm{CH}=\mathrm{CH}_{2}+\mathrm{HCl}
$$

see $[1,2]$

$$
\mathrm{CH}_{3}-\mathrm{CF}_{3} \longrightarrow \mathrm{CH}_{2}=\mathrm{CF}_{2}+\mathrm{HF}
$$

see $[3-5]$

$$
\left(\mathrm{CH}_{3}\right)_{3} \mathrm{C}-\mathrm{OH} \longrightarrow\left(\mathrm{CH}_{3}\right)_{2}=\mathrm{C}=\mathrm{CH}_{2}+\mathrm{H}_{2} \mathrm{O}
$$

see [6], that the single transition state on the surface does not lead directly to the formation of the elimination products, but it is rather transferred prior to the elimination step to 


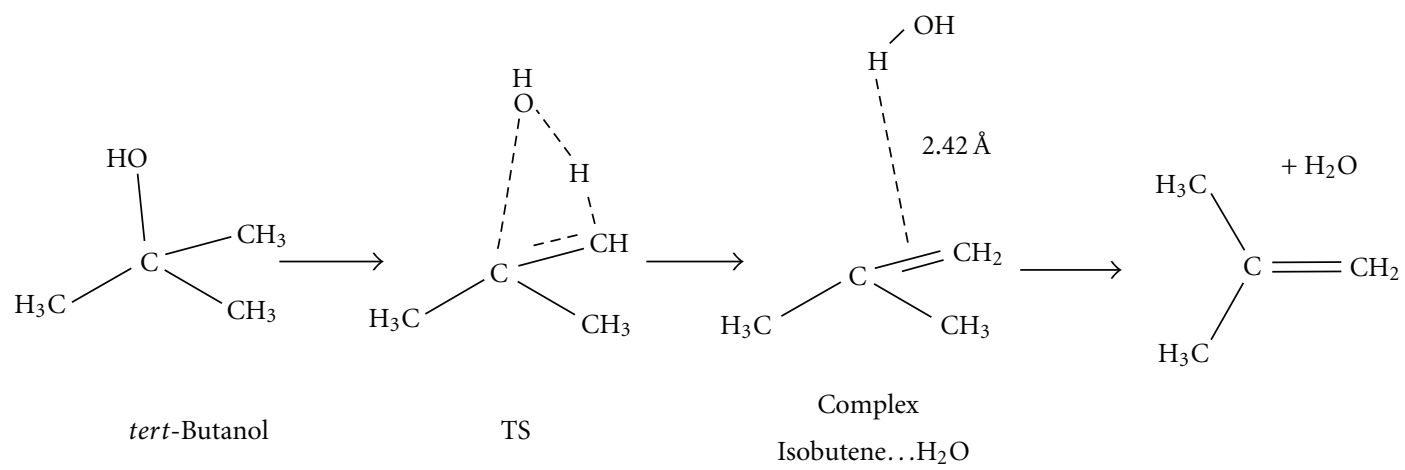

FIGURE 1: Reaction pathway of the tert-butanol $\rightarrow$ isobutene $+\mathrm{H}_{2} \mathrm{O}$ process.

a complex molecule that has, from all respects, the properties of an intermediate. The future eliminated molecule is remote from the remaining part of the complex relative to the reacting molecule, but it is still a part of the original structure.

\section{Computational Details}

The inability of most common DFT methods to accurately predict the potential energy surfaces of weak noncovalent interactions is well known [13]. The weak electrostatic interactions are difficult to estimate using most theoretical methods, including also $a b$ initio methods such as MP2 [13]. In many cases DFT methods give binding energy with considerably smaller errors than MP2 [13]. For these reasons, we decided to use a number of quantum chemical computational methods owing to our desire to prove without any doubt that the intermediate complex is still an independent entity and we cannot trust a single method.

In this investigation geometry optimization and harmonic frequencies evaluation were performed using different methods including DFT, MP2, and CCSD with aug-cc-pVDZ $[14,15]$ basis set. We used long range corrected functionals such as CAM-B3LYP (new hybrid exchange-correlation functional using the Coulomb-attenuating method) [16] and LC-wPBE (long-range-corrected version of wPBE) [1720]. Better agreement between calculated and experimental energy barriers, in many cases, could be achieved by $\operatorname{CCSD}(\mathrm{T})$ method with optimized structures by one of several hybrid functionals, including long-range correction (CAM-B3LYP or LC-wPBE). The two methods B2PLYP [21] and mPW2PLYP [22] where performance for noncovalent bound system reach relatively large computational accuracy have also been used. Both methods used, that is, B2PLYP$\mathrm{D}$ and mPW2PLYP-D, include also empirical dispersion correction [23].

The following are the methods of calculation that have been used in the present study, including the symbols (a, b, c, and d) that appear in the tables. The additional methods that have also been discussed before gave approximately the same results:
(a) CAM-B3LYP/aug-ccPVDZ,
(b) $\operatorname{CCSD}(\mathrm{T}) / / \mathrm{CAM}-\mathrm{B} 3 \mathrm{LYP} /$ aug-ccPVDZ,

(c) LC-wPBE/aug-ccPVDZ,

(d) $\operatorname{CCSD}(\mathrm{T}) / / \mathrm{LC}-w P B E /$ aug-ccPVDZ.

Basis set superposition error (BSSE) calculations for noncovalent interactions in intermolecular complexes were done using counterpoise (CP) correction proposed by Boys and Bernardi $[24,25]$. The calculations were carried out using the Gaussian-09 package [26].

The nature of the van der Walls interactions in the examples shown in this study is interactions between the slightly positively charges hydrogen atom and the $\pi$-electrons of the $\mathrm{C}=\mathrm{C}$ double bonds.

Evaluation of the high-pressure limit first-order rate constants of the eliminations based on the quantum chemical calculations was done in order to compare the calculated results to existing experimental data. For this the relation

$$
k_{\infty}=\sigma\left(\frac{k T}{h}\right) \exp \left(\frac{\Delta S^{\#}}{R}\right) \exp \left(\frac{-\Delta H^{\#}}{R T}\right)
$$

was used $[27,28]$, where $\sigma$ is the degeneracy of the reaction coordinate. Since we deal with unimolecular reactions, $\Delta H^{\#}=\Delta E^{\#}$, where $\Delta E^{\#}$ is the energy difference between the transition state and the reactant.

\section{Results}

3.1. Tert-Butanol $\rightarrow$ Isobutene $+\mathrm{H}_{2} \mathrm{O}$. Figure 1 shows a schematic reaction pathway taken from the potential energy surface of the reaction: tert-butanol $\rightarrow$ isobutene $+\mathrm{H}_{2} \mathrm{O}$.

As can be seen, the distance between a hydrogen atom of the $\mathrm{H}_{2} \mathrm{O}$ group and the center of the $\mathrm{C}=\mathrm{C}$ double bond is very large, $\sim 2.4 \AA$ (calculate at CAM-B3LYP/aug-ccPVDZ level of theory), that is far above a normal bond distance involving hydrogen atoms, but nevertheless it is still part of the original tert-butanol. As has already been mentioned before, the van der Walls interaction in the system is the interaction between the slightly positively charged hydrogen atom and the $\pi$ electrons of the $\mathrm{C}=\mathrm{C}$ double bonds.

In Table 1 a comparison between the entropy of the complex intermediate, the original reactant, and the final products is shown, for four different quantum chemical methods that have been used in the calculations. The entropy of 
TABLE 1: Entropy and free energy values of the tert-butanol $\rightarrow$ isobutene $+\mathrm{H}_{2} \mathrm{O}$ reaction.

\begin{tabular}{lccccc}
\hline Method of & Molecule & \multicolumn{2}{c}{ Complex } & \multicolumn{2}{c}{ Isobutene $+\mathrm{H} 2 \mathrm{O}$} \\
calculation $^{1}$ & $S^{2}$ & $S$ & $\Delta G^{3}$ & $S$ & $\Delta G$ \\
\hline (a) & 77.32 & 92.93 & -6.74 & 115.64 & -20.71 \\
(b) & & & -7.68 & & -26.91 \\
(c) & 77.29 & 93.34 & -3.17 & 115.67 & -23.76 \\
(d) & & & -7.72 & & -26.91 \\
\hline
\end{tabular}

${ }^{1}$ See Section 2.

${ }^{2}$ Entropies at 1100 , in $\mathrm{cal} /(\mathrm{K} \mathrm{mol})$.

${ }^{3}$ Free energy at $1100 \mathrm{~K}$, in $\mathrm{kcal} / \mathrm{mol}, \Delta G$ is calculated relative free energy in the molecule.

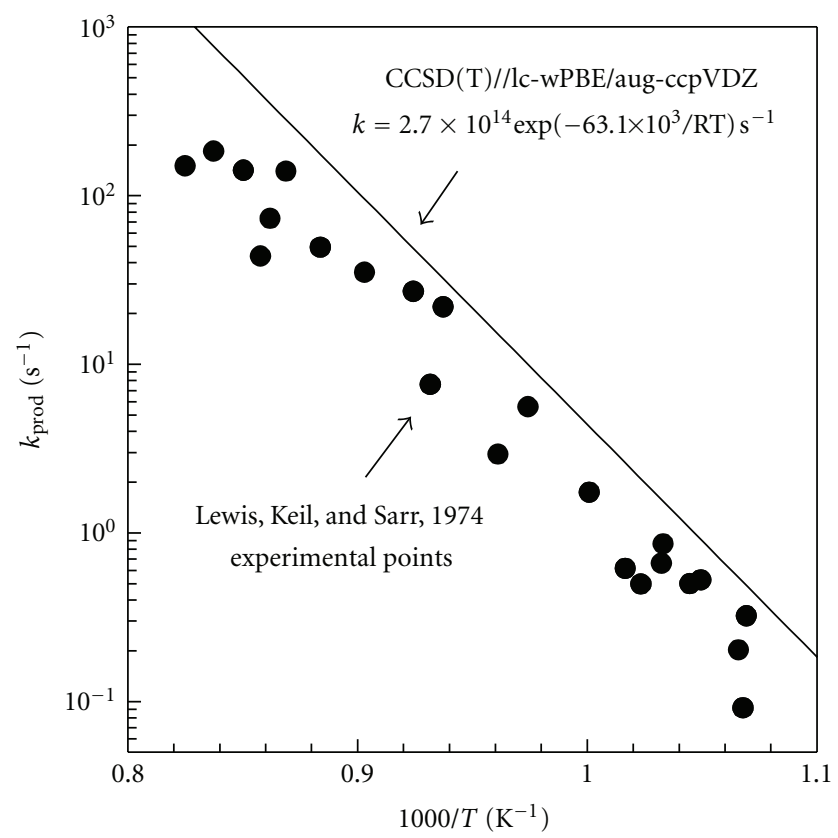

FIGURE 2: Comparison between the experimental and the calculated data points for tert-butanol decomposition.

the complex, although higher than that of the original tertbu-tanol in view of its loose structure, is still much lower than that of the sum of the entropies of the two elimination products, isobutene and water. The additional rotational and the Sackur-Tetrode translational entropies in the two final elimination products are high as can be seen in the Table 1 .

Table 2 shows a comparison between three relevant frequencies of a free $\mathrm{H}_{2} \mathrm{O}$ molecule and those of the $\mathrm{H}_{2} \mathrm{O}$ group that is attached to the complex (Figure 1). The frequencies are not the same, indicating again that there are two different $\mathrm{H}_{2} \mathrm{O}$ entities on the potential energy surface: one is still part of the original tert-butanol and one is a free entity.

Rate constant for the unimolecular elimination tertbutanol $\rightarrow$ isobutene $+\mathrm{H}_{2} \mathrm{O}$ calculated using CCSD $(\mathrm{T}) / / \mathrm{LC}$ wPBE/aug-ccPVDZ method is compared to the available experimental values [6] (see Figure 2). A degeneracy of 9 in the reaction coordinate was assumed in the calculations. The agreement is reasonably good.
TABLE 2: The frequencies (in $\mathrm{cm}^{-1}$ ) of the complex in comparison with the corresponding ones in free $\mathrm{H}_{2} \mathrm{O}$ (at CAM-B3LYP/augccPVDZ level of theory). In parenthesis the value of peak intensity is also presented $(\mathrm{KM} / \mathrm{mole})$.

\begin{tabular}{lcc}
\hline Complex & Free $\mathrm{H}_{2} \mathrm{O}$ & Assignment \\
\hline $1624.0(33)$ & $1612.0(76)$ & HOH bend \\
$3754.5(201)$ & $3835.7(7)$ & OH sym. stretch \\
$3915.4(130)$ & $3944.7(73)$ & OH asym. stretch \\
\hline
\end{tabular}

TABLe 3: Entropy and free energy values for 1,1,1-trifluoroethane $\rightarrow$ 1,2-difluoroethene + HF reaction.

\begin{tabular}{lccccc}
\hline Method of & Molecule & \multicolumn{2}{c}{ Complex } & \multicolumn{2}{c}{ Difluoroethene + HF } \\
calculation $^{1}$ & $S^{2}$ & $S$ & $\Delta G^{3}$ & $S$ & $\Delta G$ \\
\hline (a) & 70.84 & 82.81 & 15.85 & 106.18 & -6.24 \\
(b) & & & 14.85 & & -7.25 \\
(c) & 70.80 & 82.86 & 19.23 & 106.14 & -3.50 \\
(d) & & & 14.67 & & -7.24 \\
\hline
\end{tabular}

${ }^{1}$ See Section 2.

${ }^{2}$ Entropies at $1100 \mathrm{~K}$, in $\mathrm{cal} /(\mathrm{K} \mathrm{mol})$.

${ }^{3}$ Free energy at $1100 \mathrm{~K}$, in $\mathrm{kcal} / \mathrm{mol} . \Delta G$ is the calculated relative free energy in the molecule.

3.2. 1,1,1-Trifluoroethane $\rightarrow$ 1,1-Difluoroethylene $+H F$. Figure 3 shows a schematic reaction pathway for 1,1,1-trifluoroethane $\rightarrow$ 1,1-difluoro-ethylene $+\mathrm{HF}$, taken from the potential energy surface of this reaction.

The distance between the hydrogen atom of the HF entity to the $\mathrm{C}=\mathrm{C}$ double bond in the complex is very large, more than $2 \AA$ (as calculate at CAM-B3LYP/aug-ccPVDZ level of theory), that is, incompatible with $\mathrm{H}$ atom bonds namely, far above a normal bond distance, but nevertheless, it is still part of the original 1,1,1-trifluoroethane.

In Figure 4 we show the structure of the complex in detail and the distribution of the partial electrostatic charge in the complex calculated using the Mulliken method. As can be seen, a straight line that extends from the $\mathrm{H}-\mathrm{F}$ bond meets the $\mathrm{C}=\mathrm{C}$ double bond very close to the carbon atom of the $\mathrm{CH}_{2}$ group owing to the large difference in the partial charge on the $\mathrm{CF}_{2}$ group ( -0.32 elementary units) and the $\mathrm{CH}_{2}$ group $(+0.4)$ units that attracts the positively charged hydrogen atom.

In Table 3, a comparison between the entropy of the complex intermediate and the final products is shown. The entropy of the complex, although higher than that of the original trifluoroethane, is much lower than that of the sum of the entropies of the two elimination products, difluoroethylene and HF, indicating again that the HF in the complex is not a free entity. Moreover, the vibrational stretch frequency of HF in the complex is $3843 \mathrm{~cm}^{-1}$, whereas it is $4089 \mathrm{~cm}^{-1}$ in the free HF molecule.

Rate constant for the unimolecular elimination 1,1,1-trifluoroethane $\rightarrow 1$,1-difluoroethylene $+\mathrm{HF}$ reaction was calculated using $\operatorname{CCSD}(\mathrm{T}) / / \mathrm{lc}-\mathrm{wPBE} /$ aug-cc-pVDZ method as compared to the experimental values [3] (see Figure 5). As can be seen the agreement is very good. 


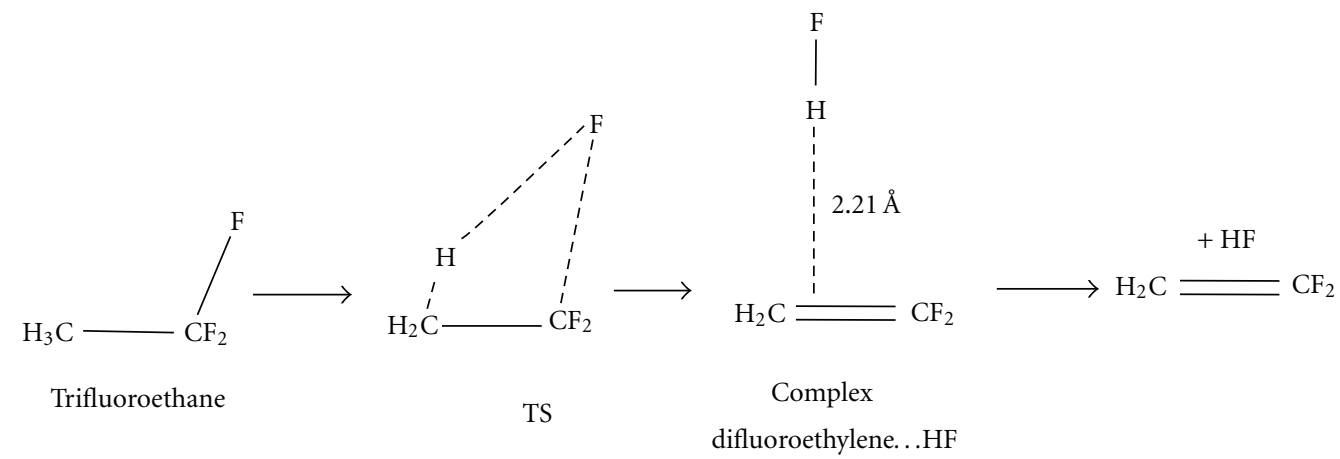

FIGURE 3: Reaction pathway for trifluoroethane $\rightarrow$ 1,1-difluoroethylene + HF process.

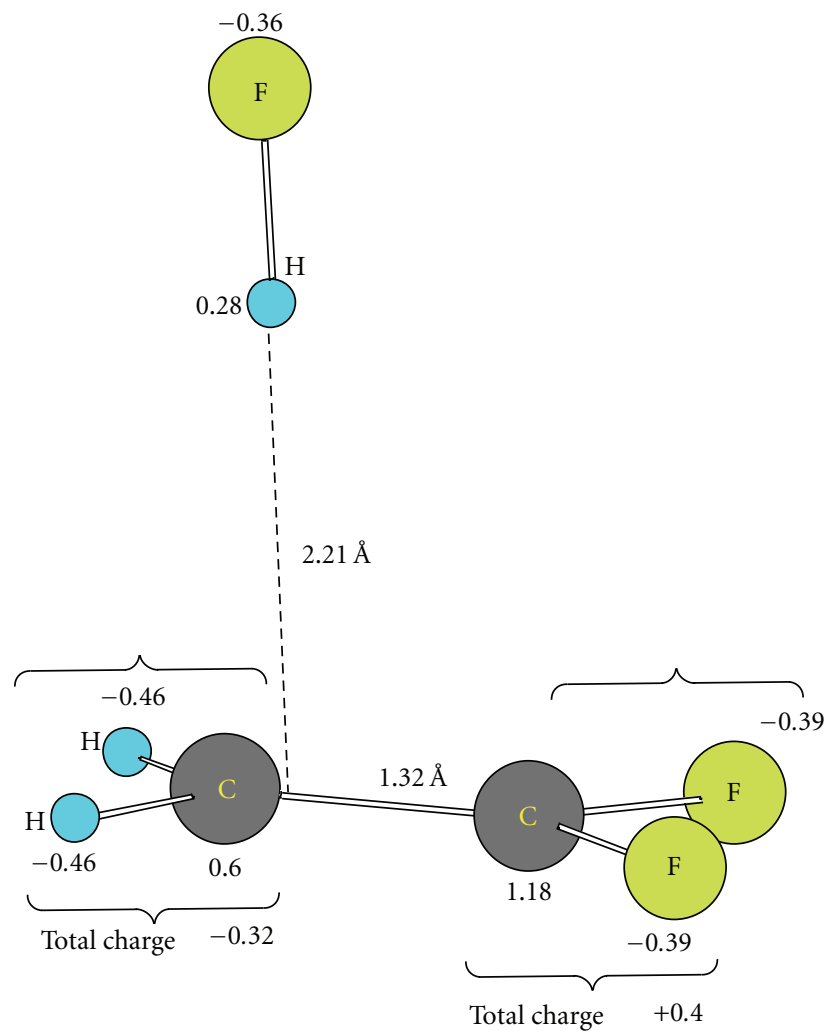

Figure 4: Detailed structure of the complex intermediate in the trifluoroethane $\rightarrow$ 1,1-difluoroethylene + HF process.

3.3. 1-Chloropropane $\rightarrow$ Propylene $+\mathrm{HCl}$. Figure 6 shows a schematic reaction pathway of the reaction: $\mathrm{n}$-chloropropane $\rightarrow$ propylene $+\mathrm{HCl}$.

Similar to the $\mathrm{CH}_{3}-\mathrm{CF}_{3} \rightarrow \mathrm{CH}_{2}=\mathrm{CF}_{2}+\mathrm{HF}$ reaction, the distance between the $\mathrm{H}$ atom in the $\mathrm{HCl}$ entity and the center of the $\mathrm{C}=\mathrm{C}$ double bond in the complex is very large, $\sim 2.4 \AA$ (as calculated at CAM-B3LYP/aug-ccPVDZ level of theory), that is far above a normal bond distance, but nevertheless it is still part of the original $n$-chloropropane.

Figure 7 shows the structure of the complex in detail and the distribution of the partial electrostatic charge in the complex calculated using the Mulliken method. In this

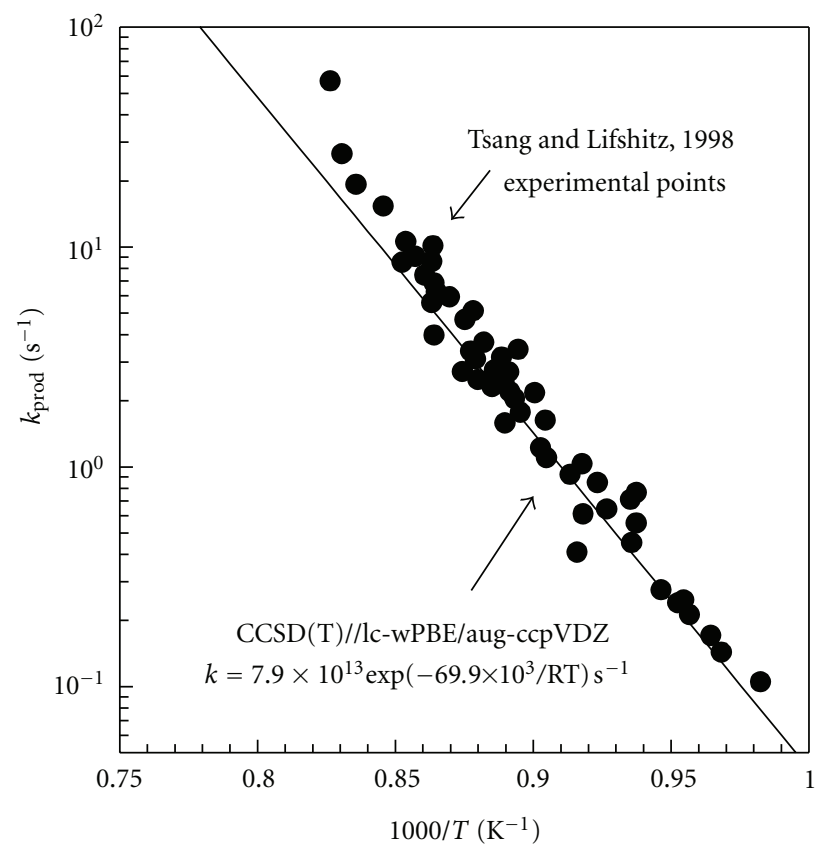

FIGURE 5: Comparison between the experimental and the calculated data points for the 1,1,1-trifluoroethylene $\rightarrow$ 1,1-difluoroethylene + HF reaction.

system, the extension of the $\mathrm{H}-\mathrm{Cl}$ line meets the $\mathrm{C}=\mathrm{C}$ double bond close to the middle of the $\mathrm{C}=\mathrm{C}$ double bond in view of the very close positive fractional charge on the two carbon atoms, namely, +0.90 and +0.98 . Here the interaction is merely between the hydrogen atom and the $\pi$ electrons of the $\mathrm{C}=\mathrm{C}$ double bond.

In Table 4 a comparison between the entropy of the complex intermediate and the final products is shown, indicating also the quantum chemical methods that have been used. As can be seen, the entropy of the complex, although higher than that of the original n-chloropropane, is much lower than that of the sum of the entropies of the two elimination products. An additional support for the fact that the $\mathrm{HCl}$ in the complex is not a free entity is the difference between the stretch frequency of $\mathrm{HCl}$ in the complex and 


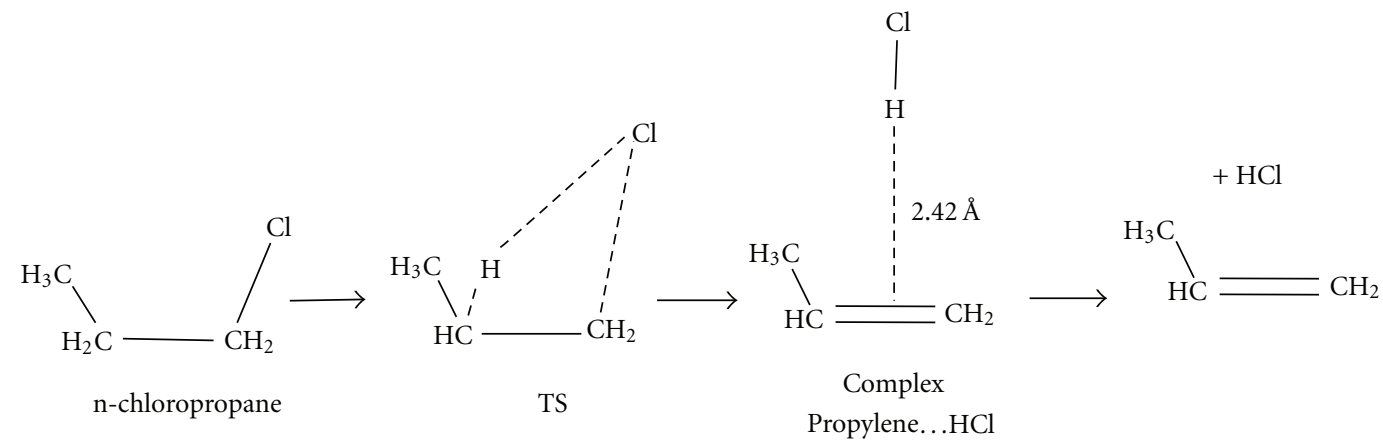

FIgURE 6: Reaction pathway for $\mathrm{n}$-chloropropane $\rightarrow$ propylene $+\mathrm{HCl}$ process.

TABLE 4: Entropy and free energy values of the n-chloropropane $\rightarrow$ propylene $+\mathrm{HCl}$ reaction.

\begin{tabular}{lccccc}
\hline Method of & Molecule & \multicolumn{2}{c}{ Complex } & \multicolumn{2}{c}{ Propylene + HCl } \\
calculation $^{1}$ & $S^{2}$ & $S$ & $\Delta G^{3}$ & $S$ & $\Delta G$ \\
\hline (a) & 72.97 & 84.37 & -2.09 & 107.85 & -26.86 \\
(b) & 0.0 & & -3.30 & & -26.80 \\
(c) & 72.82 & 84.44 & 2.22 & 107.86 & -20.95 \\
(d) & 0.0 & & -3.66 & & -24.38
\end{tabular}

${ }^{1}$ See the Section 2.

${ }^{2}$ Entropies at $1100 \mathrm{~K}$, in $\mathrm{cal} /(\mathrm{K} \mathrm{mol})$.

${ }^{3}$ Free energy at $1100 \mathrm{~K}$, in $\mathrm{kcal} / \mathrm{mol} . \Delta G$ is the calculated relative free energy in the molecule.

in the free molecule. Whereas the frequency in the complex $2749 \mathrm{~cm}^{-1}$, it is $2960 \mathrm{~cm}^{-1}$ in the free molecule.

Rate constant for the unimolecular n-chloropropane $\rightarrow$ propylene $+\mathrm{HCl}$ elimination was calculated using $\operatorname{CCSD}(\mathrm{T}) / /$ lc-wPBE/aug-cc-pVDZ method as compared to the experimental values [1] (see Figure 8). The calculated rate constant is approximately a factor of three higher than the experimental points.

\section{Discussion and Conclusions}

The conclusion regarding the existence of intermediate complex molecules in addition to their presence on the potential energy surfaces was reached on the basis of the following three major indications.

(1) The entropy of the intermediate (complex), although higher than that of the reacting molecule as it has a looser structure, is far from that of the two decomposition products, owing to the fact that additional rotations and the high translational Sackur-Tetrode entropy that the two reaction products posses are not added to the entropy of the complex.

(2) Among the 3n-6 vibrational frequencies, there are no imaginary frequency indicating that the complex molecule is an intermediate that stays at a local minimum.

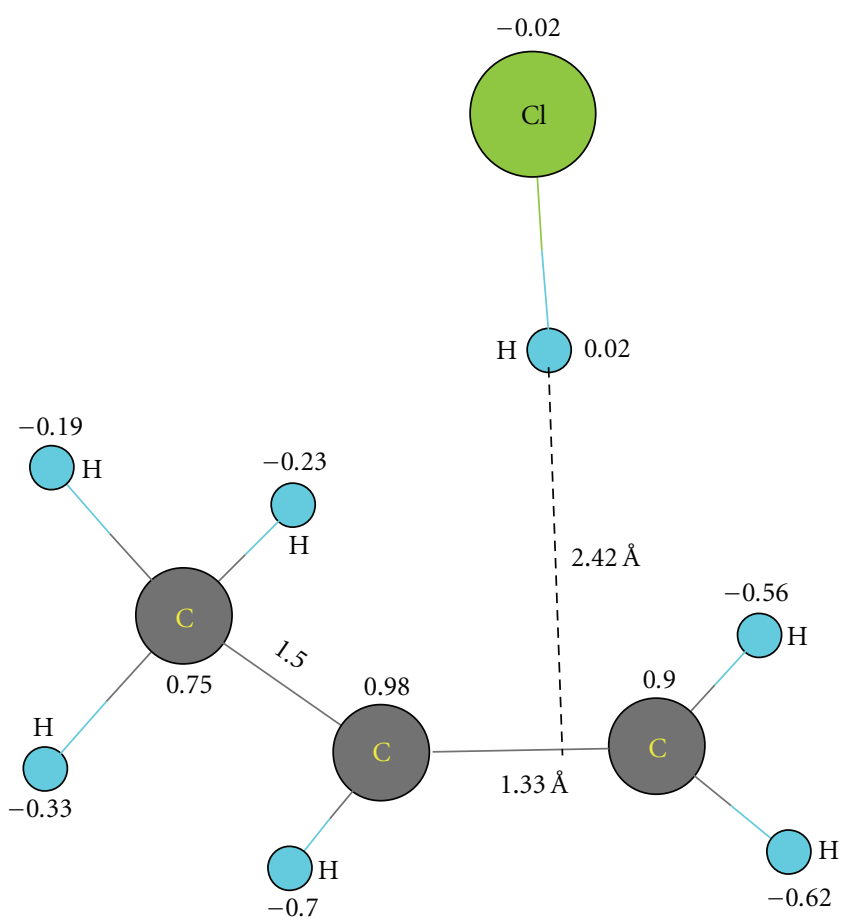

Figure 7: Detailed structure of the complex intermediate in the nchloropropane $\rightarrow$ propylene $+\mathrm{HCl}$ reaction.

(3) The calculated energy level of the complex is around $2 \mathrm{kcal} / \mathrm{mol}$ below that of the two decomposition products.

The question that arises is to what extent the complex intermediate plays a role from kinetics viewpoint, namely, whether the kinetics of the decomposition is affected by the existence of this complex. We have tried to locate a transition state going from the complex to the decomposition products, using a variety of methods of calculations but they were unsuccessful.

In view of the fact that the energy of the transition states connecting the original molecule with the complex is high, the complex must be, to some extent, vibrationally excited, even at high pressures when the deexcitation is efficient and 


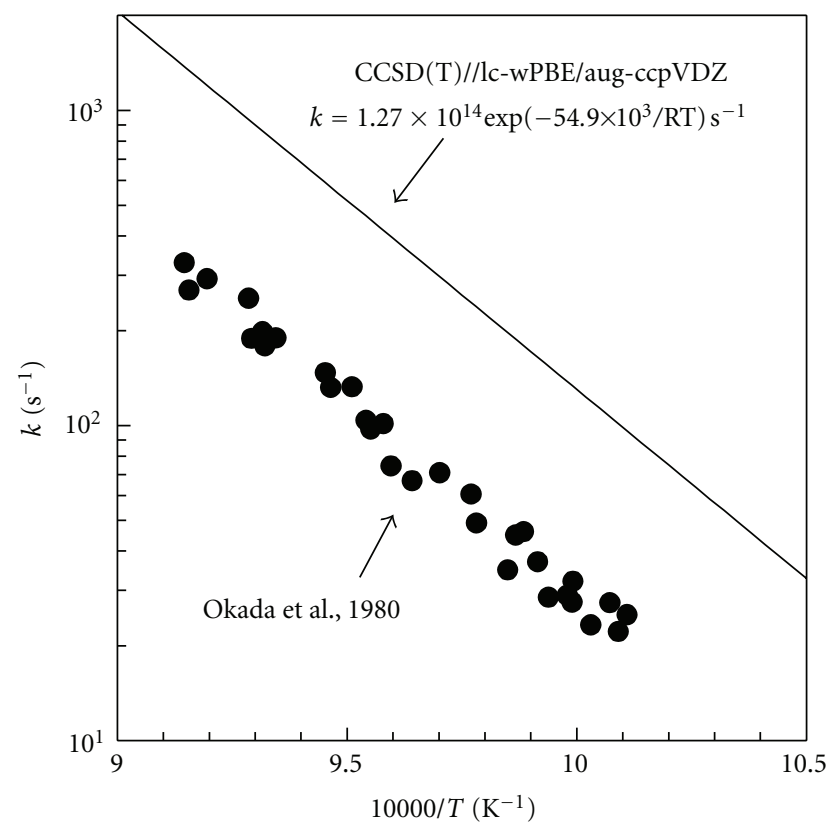

FIGURE 8: Comparison between the experimental and the calculated data points for the reaction $\mathrm{CH}_{3}-\mathrm{CH}_{2}-\mathrm{CHCl} \rightarrow \mathrm{CH}_{3}-\mathrm{CH}=\mathrm{CH}_{2}+$ $\mathrm{HCl}$.

particularly so when the single bond that has to be broken is concerned. It is thus possible that the transition to the decomposition products bypasses the complex although the quantum chemical calculations clearly support the fact that it is part of the potential energy surface of the decomposition process. It should be added that the zero-point energies of the vibrational mode in the long weak bonds of the complex molecules are $0.17,0.15,0.21 \mathrm{kcal} / \mathrm{mole}$ in tertbutanol, 1,1,1-trifluoroethane, and 1-chloropropane, respectively. This means that at very low temperatures when there are no excited levels the complex is stable. However, the question as to whether the existence of the complex molecule has a kinetics meaning is a question of semantics.

\section{References}

[1] K. Okada, E. Tshuikow-Roux, and P. J. Evans, "Single-pulse shock-tube study of the thermal decomposition of ethyl fluoride and N-propyl chloride," Journal of Physical Chemistry, vol. 84, pp. 467-471, 1980.

[2] P. J. Evans, T. Ichimura, and E. Tschuikow-Roux, "A comparison of two single-pulse shock-tube techniques: the thermal decomposition of ethyl chloride and n-propyl chloride," International Journal of Chemical Kinetics, vol. 10, no. 8, pp. 855-869, 1978.

[3] W. Tsang and A. Lifshitz, "Kinetic stability of 1,1,1-trifluoroethane," International Journal of Chemical Kinetics, vol. 30, no. 9, pp. 621-628, 1998.

[4] P. V. Mitin, V. G. Barabanov, and G. V. Volkov, "Kinetics of the thermal decomposition of 1,1-difluoro-1-chloroethane and 1,1,1-trifluoroethane," Kinetics and Catalysis, vol. 29, pp. 1279-1286, 1988.

[5] B. R. Giri and R. S. Tranter, "Dissociation of 1,1,1-trifluoroethane behind reflected shock waves: shock tube/time-of-flight mass spectrometry experiments," Journal of Physical Chemistry A, vol. 111, no. 9, pp. 1585-1592, 2007.

[6] D. Lewis, M. Keil, and M. Sarr, "Gas phase thermal decomposition of tert-butyl alcohol," Journal of the American Chemical Society, vol. 96, pp. 4398-4404, 1974.

[7] A. Heikkila, "Matrix isolation and ab initio studies of 1:1 hydrogen-bonded complexes $\mathrm{HCN}-\mathrm{H}_{2} \mathrm{O}$ and $\mathrm{HNC}-\mathrm{H}_{2} \mathrm{O}$ produced by photolysis of formaldoxime," Journal of Physical Chemistry A, vol. 103, no. 16, pp. 2945-2951, 1999.

[8] G. Larsen, Z. K. Ismail, B. Herreros, and R. D. Parra, "Benzene/tert-butyl alcohol interactions. 1. A theoretical and experimental study," Journal of Physical Chemistry A, vol. 102, no. 24, pp. 4734-4741, 1998.

[9] R. L. Rowley, C. M. Tracy, and T. A. Pakkanen, "Potential energy surfaces for small alcohol dimers. II. Propanol, isopropanol, t -butanol, and sec-butanol," Journal of Chemical Physics, vol. 127, no. 2, Article ID 025101, 2007.

[10] P. K. Mandal, D. J. Ramdass, and E. Arunan, "Rotational spectra and structure of the Ar2-H2S complex: pulsed nozzle Fourier transform microwave spectroscopic and ab initio studies," Physical Chemistry Chemical Physics, vol. 7, no. 14, pp. 2740-2746, 2005.

[11] F. Dubnikova and A. Lifshitz, "Molecular hydrogen elimination from 2,5-dihydrofuran, 2,3-dihydrofuran, and 2-methyl2,5-dihydrofuran: quantum chemical and kinetics calculations," International Journal of Chemical Kinetics, vol. 33, no. 11, pp. 685-697, 2001.

[12] A. M. El-Nahas, A. H. Mangood, H. Takeuchi, and T. Taketsugu, "Thermal decomposition of 2-butanol as a potential nonfossil fuel: a computational study," Journal of Physical Chemistry A, vol. 115, no. 13, pp. 2837-2846, 2011.

[13] E. R. Johnson, I. D. Mackie, and G. A. DiLabio, "Dispersion interactions in density-functional theory," Journal of Physical Organic Chemistry, vol. 22, no. 12, pp. 1127-1135, 2009.

[14] T. H. Dunning Jr, "Gaussian basis sets for use in correlated molecular calculations. I. The atoms boron through neon and hydrogen," The Journal of Chemical Physics, vol. 90, no. 2, pp. 1007-1023, 1989.

[15] R. A. Kendall, T. H. Dunning, and R. J. Harrison, "Electron affinities of the first-row atoms revisited. Systematic basis sets and wave functions," The Journal of Chemical Physics, vol. 96, no. 9, pp. 6796-6806, 1992.

[16] T. Yanai, D. P. Tew, and N. C. Handy, "A new hybrid exchangecorrelation functional using the Coulomb-attenuating method (CAM-B3LYP)," Chemical Physics Letters, vol. 393, no. 1-3, pp. 51-57, 2004.

[17] Y. Tawada, T. Tsuneda, S. Yanagisawa, T. Yanai, and K. Hirao, "A long-range-corrected time-dependent density functional theory," Journal of Chemical Physics, vol. 120, no. 18, pp. 84258433, 2004.

[18] O. A. Vydrov and G. E. Scuseria, "Assessment of a long-range corrected hybrid functional," Journal of Chemical Physics, vol. 125, no. 23, Article ID 234109, pp. 1-9, 2006.

[19] O. A. Vydrov, J. Heyd, A. V. Krukau, and G. E. Scuseria, "Importance of short-range versus long-range Hartree-Fock exchange for the performance of hybrid density functionals," Journal of Chemical Physics, vol. 125, no. 7, Article ID 074106, pp. 1-9, 2006.

[20] O. A. Vydrov, G. E. Scuseria, and J. P. Perdew, "Tests of functionals for systems with fractional electron number," Journal of Chemical Physics, vol. 126, no. 15, Article ID 154109, pp. 1-9, 2007.

[21] S. Grimme, "Semiempirical hybrid density functional with perturbative second-order correlation," Journal of Chemical Physics, vol. 124, no. 3, Article ID 034108, pp. 1-6, 2006. 
[22] T. Schwabe and S. Grimme, "Towards chemical accuracy for the thermodynamics of large molecules: new hybrid density functionals including non-local correlation effects," Physical Chemistry Chemical Physics, vol. 8, no. 38, pp. 4398-4401, 2006.

[23] T. Schwabe and S. Grimme, "Double-hybrid density functionals with long-range dispersion corrections: higher accuracy and extended applicability." Physical Chemistry Chemical Physics, vol. 9, no. 26, pp. 3397-3406, 2007.

[24] S. F. Boys and F. Bernardi, "The calculation of small molecular interactions by the differences of separate total energies. Some procedures with reduced errors," Molecular Physics, vol. 19, no. 4, pp. 553-566, 1970.

[25] S. Simon, M. Duran, and J. J. Dannenberg, "How does basis set superposition error change the potential surfaces for hydrogen-bonded dimers?" Journal of Chemical Physics, vol. 105, no. 24, pp. 11024-11031, 1996.

[26] M. J. Frisch, G. W. Trucks, H. B. Schlegel et al., Gaussian 09, Revision A.1, Gaussian, Inc., Wallingford, Conn, USA, 2009.

[27] H. Eyring, "The activated complex in chemical reactions," Journal of Chemical Physics, vol. 3, pp. 107-115, 1935.

[28] M. G. Evans and M. Polanyi, "Some applications of the transition state method to the calculation of reaction velocities, especially in solution," Transactions of the Faraday Society, vol. 31, pp. 875-894, 1935. 


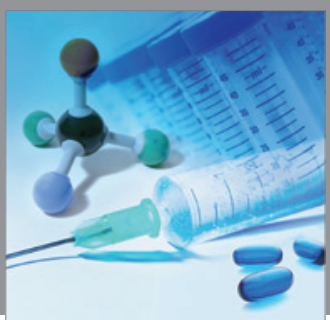

International Journal of

Medicinal Chemistry

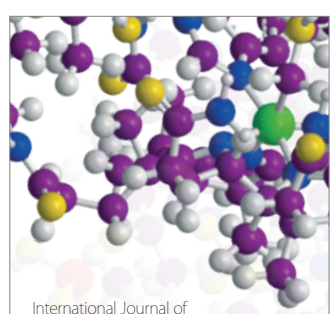

Carbohydrate Chemistry

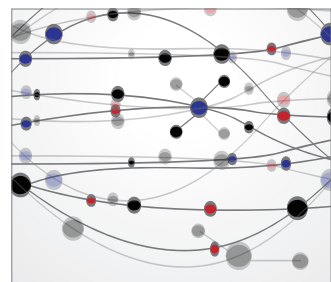

The Scientific World Journal
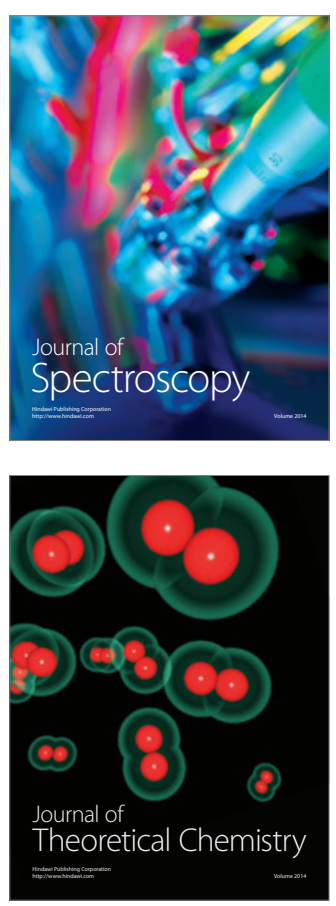
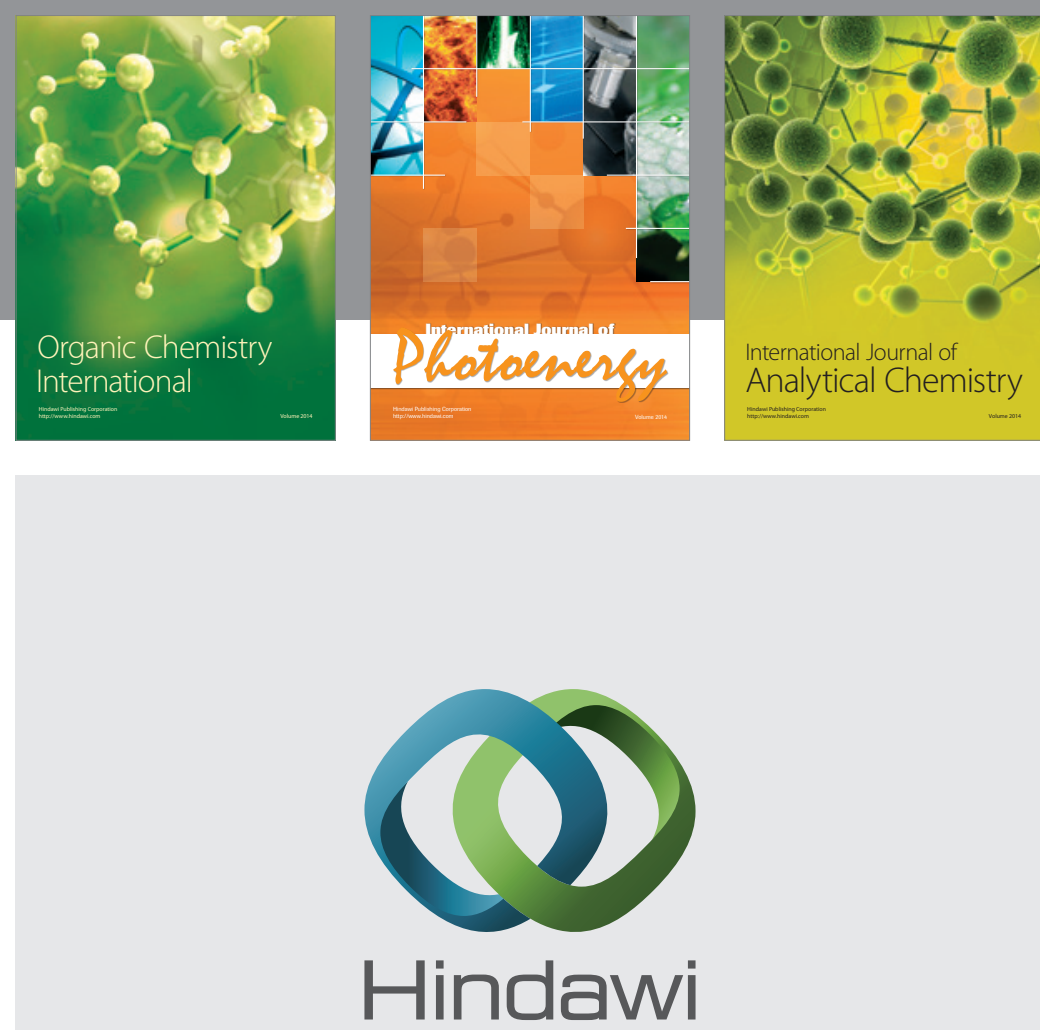

Submit your manuscripts at

http://www.hindawi.com
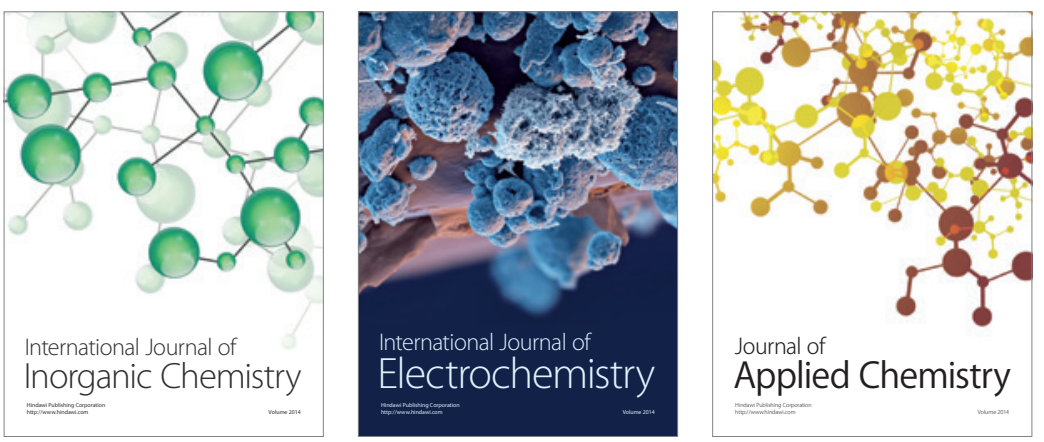

Journal of

Applied Chemistry
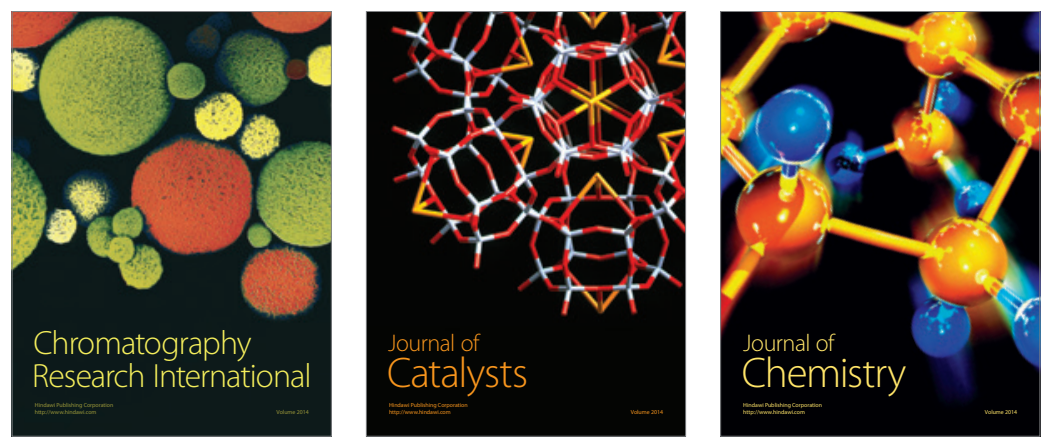
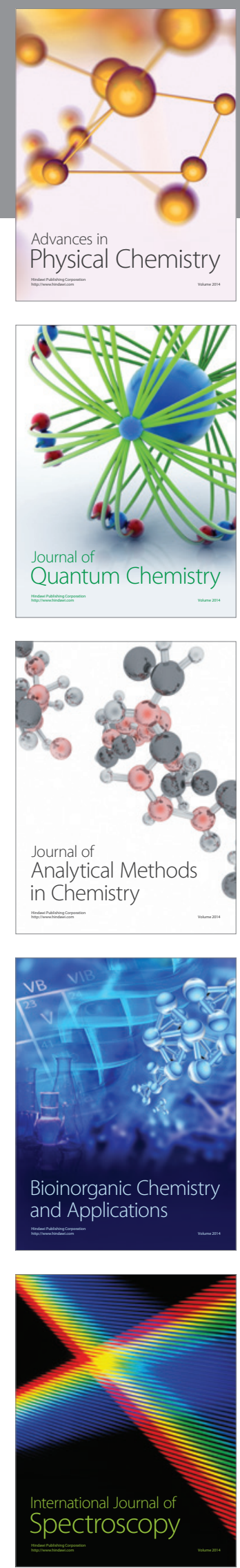